\title{
Adaptabilidade e estabilidade de genótipos de amendoim de porte rasteiro
}

\author{
Eder Jorge de Oliveira(1) ${ }^{(1)}$ Ignácio José de Godoy(1), Andrea Rocha Almeida de Moraes ${ }^{(1)}$, \\ Antônio Lúcio Mello Martins ${ }^{(2)}$, José Carlos Vila Nova Alves Pereira ${ }^{(3)}$, Nelson Bortoletto ${ }^{(4)}$ e Francisco Seiiti Kasai(5)
}

\begin{abstract}
(1)Instituto Agronômico, Centro de Grãos e Fibras, Caixa Postal 28, CEP 13001-970 Campinas, SP. E-mail: eder@iac.sp.gov.br, ijgodoy@iac.sp.gov.br, andreamoraes@gmail.com (2)Agência Paulista de Tecnologia Agropecuária (APTA), Pólo Regional de Desenvolvimento Tecnológico dos Agronegócios do Centro Norte, Caixa Postal 24, CEP 15830-000 Pindorama, SP. E-mail: Imartins@aptaregional.sp.gov.br (3)APTA, Pólo Regional de Desenvolvimento Tecnológico dos Agronegócios do Centro Leste, Caixa Postal 271, CEP 14001-970 Ribeirão Preto, SP. E-mail: jcap@aptaregional.sp.gov.br (4)APTA, Pólo Regional de Desenvolvimento Tecnológico dos Agronegócios do Noroeste Paulista, Caixa Postal 61, CEP 15500-970 Votuporanga, SP. E-mail: nan.iac@votuporanga.com.br (5)APTA, Pólo Regional de Desenvolvimento Tecnológico dos Agronegócios da Alta Paulista, Caixa Postal 191, CEP 17800-000 Adamantina, SP. E-mail: fskasai@aptaregional.sp.gov.br
\end{abstract}

\begin{abstract}
Resumo - O comportamento produtivo de genótipos de amendoim (Arachis hypogaea L.) foi avaliado a partir de três diferentes métodos de adaptabilidade e estabilidade. Foram avaliadas 18 linhagens e as cultivares Runner IAC 886 e IAC Caiapó, quanto à produtividade de vagens (PV) e peso de 100 grãos (P100G), em dez ensaios de campo, no Estado de São Paulo, utilizando-se os métodos de ecovalência, Eberhart \& Russel e Lin \& Binns. Foram observadas diferenças significativas para o efeito de genótipo (G), ambiente (E) e interação (GxE), para as duas variáveis. As linhagens L123, L137 e L150 foram as mais produtivas, com comportamento estável e previsível. O método de Lin \& Binns mostrou-se mais discriminante na avaliação da PV e do P100G, enquanto o método de Eberhart \& Russel foi mais útil na indicação das linhagens com adaptabilidade ampla ou específica a determinados ambientes. Os métodos de Lin \& Binns e de Eberhart \& Russel foram mais informativos que o de ecovalência, na predição do comportamento das linhagens para as duas características. Foi encontrada correlação negativa entre a PV e o parâmetro $\mathrm{P}_{\mathrm{i}}$, e positiva entre $\delta_{\mathrm{ij}}$ e $\omega_{\mathrm{i}}$. Para P100G, detectaram-se as mesmas correlações de $\mathrm{PV}$, além da correlação negativa entre $\mathrm{P}_{\mathrm{i}}$ e $\omega_{\mathrm{i}}$.
\end{abstract}

Termos para indexação: Arachis hypogaea, interação genótipo e ambiente, produtividade.

\section{Adaptability and stability of peanut genotypes of runner growth habit}

\begin{abstract}
The performance of peanut (Arachis hypogaea L.) genotypes was assessed using three different adaptability and stability methods. Eighteen lines and two cultivars, Runner IAC 886 and IAC Caiapó, were evaluated for pod yield (PY) and one hundred kernel weight (HKW), in ten field trials in the State of São Paulo, using ecovalance, Eberhart \& Russel and Lin \& Binns methods. Significant differences for genotype (G), environment (E) and interaction (GxE) effects were observed for both variables. The lines L123, L137 and L150 were most productive and showed stable and predictable behavior. Lin \& Binns methods was more sensitive for PY and HKW, while the Eberhart \& Russel method was more useful for indicating lines with broad and specific adaptability to environmental conditions. Moreover, the Lin \& Binns and Eberhart \& Russel methods were more informative than ecovalance in predicting the behavior of genotypes for those two characteristics. Negative correlation between PY and $\mathrm{P}_{\mathrm{i}}$ parameter, and positive correlation between $\delta_{\mathrm{ij}}$ and $\omega_{\mathrm{I}}$ were found. Negative correlation was observed between one HKW and $\mathrm{P}_{\mathrm{i}}$, and between $\mathrm{P}_{\mathrm{i}}$ and $\omega_{\mathrm{i}}$.
\end{abstract}

Index terms: Arachis hypogaea, genotype and environment interaction, yield.

\section{Introdução}

O amendoim é uma importante fonte de alimento, seja como óleo ou utilizado diretamente para consumo humano. Existem muitas espécies de amendoim, porém apenas representantes da Arachis hypogaea L. foram domesticadas e amplamente cultivadas pelo homem.
No Brasil, atualmente verifica-se uma mudança no panorama nacional da cultura, em virtude da substituição das cultivares Valência e Spanish pela Runner. As primeiras cultivares podem ser diferenciadas pelo padrão comercial das vagens, número de sementes por vagem, tamanho das sementes, porte ereto e ciclo precoce (90 a 110 dias) (Godoy et al., 2001); as 
representantes do tipo 'Runner' possuem hábito de crescimento rasteiro ou semi-rasteiro, ciclo longo e maior potencial produtivo.

O Programa de Melhoramento Genético do Instituto Agronômico (IAC) tem, entre outros objetivos, a obtenção de cultivares produtivas de 'Runners' com alta qualidade de grãos. Assim, a introdução dessas novas cultivares ao sistema de produção deve levar em conta seu comportamento produtivo em diferentes locais e anos de cultivo.

Segundo Allard (1971), as variações fenotípicas resultam da ação conjunta do genótipo (G), do ambiente (E) e de sua interação (GxE), que se reflete em diferenças de sensibilidade dos genótipos às variações ambientais, afetando seu comportamento. Por conseqüência, os procedimentos de seleção baseados na média de produtividade dos genótipos num dado ambiente são pouco eficientes (Hopkins et al., 1995). Assim, a interação GxE deve ser estudada para a seleção ou recomendação de cultivares.

A análise de variância (ANOVA) conjunta de experimentos é uma maneira simples de se avaliar a interação $\mathrm{GxE}$, com magnitude determinada pelo teste F. Contudo, nessa análise, não se obtêm informações pormenorizadas dos genótipos em relação às variações do ambiente. Portanto, é necessário que se promovam estudos sobre a adaptabilidade e estabilidade a fim de identificar genótipos com comportamento previsível nos diversos ambientes, e minimizar os erros de avaliação e recomendação de cultivares.

Diversos métodos de análise de adaptabilidade e estabilidade foram propostos na literatura (Eberhart \& Russel, 1966; Lin \& Binns, 1988; Crossa, 1990; Gauch \& Zobel, 1996; Magari \& Kang, 1997; Toler \& Burrows, 1998; Rosse \& Vencovsky, 2000). Segundo Cruz \& Regazzi (2001), alguns métodos são alternativos, enquanto outros são complementares, e podem ser utilizados conjuntamente.

Entre os métodos baseados em regressão linear, o de Eberhart \& Russel (1966) é amplamente utilizado. O método de Lin \& Binns (1988) é baseado em análises não paramétricas e representa uma alternativa para se estudar a interação GxE. Neste caso, os genótipos são caracterizados de acordo com o parâmetro $\mathrm{P}_{\mathrm{i}}$, que associa estabilidade e produtividade. Apesar da preferência por um ou outro método, o fato é que pode haver divergências entre eles em relação à classificação dos genótipos mais estáveis e produtivos.
Carbonell et al. (2001) avaliaram o comportamento produtivo de linhagens de feijoeiro e encontraram resultados discrepantes pelos métodos de Cruz et al. (1989) e de Lin \& Binns (1988). Em soja, Silva \& Duarte (2006) recomendam o uso de métodos baseados em coeficientes de regressão com outros fundamentados na variância da interação $\mathrm{GxE}$, ou em medidas estatísticas como a variância dos desvios da regressão, bem como o uso combinado do método de Eberhart \& Russell (1966) e da análise AMMI, em razão das correlações significativas com outros métodos e uma associação relativamente fraca entre eles.

Comparações de métodos de adaptabilidade e estabilidade das características agronômicas do amendoim, ligadas à produção, são escassas.

Este trabalho teve como objetivo avaliar o comportamento produtivo e o peso de 100 grãos de 18 linhagens de amendoim do IAC e das cultivares Runner IAC 886 e IAC Caiapó, utilizando-se os métodos de ecovalência (Wricke, 1964), Eberhart \& Russel (1966) e Lin \& Binns (1988).

\section{Material e Métodos}

A partir do cruzamento entre os genótipos L65/3-1 x Runner IAC 886 e L65/3 1 x Runner Regional, selecionou-se um conjunto de linhagens produtivas e resistentes à ferrugem e à mancha-preta, com bom padrão de vagens e de grãos.

A linhagem L65/3-1 é derivada da cultivar IAC Caiapó, com resistência moderada e múltipla a doenças foliares, enquanto o Runner Regional foi coletado de um produtor de amendoim no Estado de São Paulo; a variedade Runner IAC 886 é bem aceita dentro do sistema de produção, uma vez que apresenta alta produtividade, grãos de melhor tipificação 'Runner' e ciclo que raramente excede 130 dias, característica importante dentro do esquema de rotação da cultura com a cana-de-açúcar.

Foram realizados dez ensaios, nas estações experimentais da Agência Paulista de Tecnologia dos Agronegócios-APTA, em Ribeirão Preto, nas safras de 2002/2003, 2003/2004 e 2004/2005, Pindorama 2002/2003, 2003/2004 e 2004/2005, Adamantina 2003/2004, Campinas 2004/2005 e Votuporanga $2003 / 2004$ e $2004 / 2005$. Nestes ensaios foram avaliadas 18 linhagens, juntamente com as cultivares IAC Caipó e Runner IAC 886. 
O delineamento utilizado foi o de blocos ao acaso, com quatro repetições, com a parcela constituída por cinco linhas de $5 \mathrm{~m}$ de comprimento, considerando-se as duas linhas laterais como bordaduras. $\mathrm{O}$ espaçamento entre linhas foi de 0,9 m, com densidade de semeadura de dez plantas por metro. O plantio foi realizado em terreno corrigido com calcário, tendo-se efetuado, em todos os experimentos, adubação com $250 \mathrm{~kg} \mathrm{ha}^{-1}$ de NPK da fórmula 4-14-8. Os tratos culturais e fitossanitários foram feitos de acordo com as recomendações para a cultura (Godoy, 2005). A colheita ocorreu entre 125 e 140 dias depois do plantio. As variáveis analisadas foram a produtividade de vagens, em kg ha-1 (PV), e o peso de 100 grãos, em gramas (P100G).

Foi realizada análise de variância conjunta, para testar os efeitos de genótipos (G), ambiente (E) e a magnitude da interação GxE, para as duas variáveis. Para as análises de adaptabilidade e estabilidade, utilizaram-se os métodos de ecovalência Wricke (1964), Eberhart \& Russel (1966) e Lin \& Binns (1988).

A ecovalência $\left(\omega_{\mathrm{i}}\right)$ ou estabilidade do i-ésimo genótipo é dado por: $\omega_{\mathrm{i}}=\left[\mathrm{Y}_{\mathrm{ij}}-\overline{\mathrm{Y}}_{\mathrm{i} .}-\overline{\mathrm{Y}}_{\mathrm{j}}-\overline{\mathrm{Y}}_{. .}\right]^{2}$,

em que $Y_{i j}$ é o comportamento médio do genótipo i no ambiente j; $\bar{Y}_{i}$ e $\bar{Y}_{. j}$ são os desvios médios de genótipos e ambientes, respectivamente; e $\bar{Y}$.. é a média geral. Assim, genótipos com baixos valores de $\omega_{\mathrm{i}}$ possuem menores desvios, em relação aos ambientes, e são mais estáveis.

O método de Eberhart \& Russel (1966) utiliza a análise de regressão linear de cada genótipo com as variações ambientais, de acordo com o modelo: $Y_{\mathrm{ij}}=\mu+\beta_{\mathrm{i}} \mathrm{I}_{\mathrm{j}}$ $+\delta_{\mathrm{ij}}+\varepsilon_{\mathrm{ij}}$, em que $\mathrm{Y}_{\mathrm{ij}}$ é o comportamento do genótipo i no ambiente j; $\mu$ é a média geral; $\beta_{\mathrm{i}}$ é o coeficiente de regressão linear, que descreve a resposta do genótipo i em todos os ambientes; $\mathrm{I}_{\mathrm{j}}$ é o índice ambiental; $\delta_{\mathrm{ij}}$ é o desvio da regressão do genótipo i no ambiente j; e $\varepsilon_{\mathrm{ij}}$ é o erro associado à média.

Os coeficientes de regressão de cada genótipo em relação ao índice ambiental $\left(\beta_{\mathrm{i}}\right)$ e os desvios desta regressão $\left(\delta_{\mathrm{ij}}\right)$ proporcionam estimativas de parâmetros de adaptabilidade e estabilidade, respectivamente. Assim, a seleção de um genótipo deve ser feita, levando-se em consideração uma média elevada, um $\beta_{\mathrm{i}}$ igual ou próximo de 1 , e $\delta_{\text {ij }}$ que não difira significativamente de zero.

No método de Lin \& Binns (1988), o parâmetro $P_{i}$ define a estabilidade de um genótipo e é definido como o quadrado médio da distância entre a média de um genótipo e a resposta média máxima para todos os locais, de modo que genótipos com menores valores correspondem aos de melhor desempenho. Assim, o estimador é dado por:

$P_{i}=\sum_{j=1}^{n}\left(Y_{i j}-M_{j}\right)^{2} / 2 n$,

em que $\mathrm{P}_{\mathrm{i}}$ é a estimativa do parâmetro de estabilidade do genótipo i; $\mathrm{Y}_{\mathrm{ij}}$ é o comportamento do genótipo i no ambiente $\mathrm{j} ; \mathrm{M}_{\mathrm{j}}$ é a resposta máxima observada entre todos os genótipos no ambiente j; e n é o número de ambientes.

Para comparar os parâmetros de adaptabilidade e estabilidade fornecidos pelos três métodos, foi realizado um estudo de correlação de Spearman. Os parâmetros utilizados foram: a média geral dos genótipos, o coeficiente de regressão $\left(\beta_{\mathrm{i}}\right)$, a variância dos desvios da regressão $\left(\delta_{\mathrm{ij}}\right)$, ecovalência $\left(\omega_{\mathrm{i}}\right)$ e os valores de $\mathrm{P}_{\mathrm{i}}$.

Os métodos de ecovalência, Eberhart \& Russel e Lin \& Binns, foram implementados utilizando-se o programa Genes (Cruz, 2001). A análise de correlação de Spearman, entre os parâmetros dos três métodos, foi realizada pelo procedimento CORR do SAS Institute (2000).

\section{Resultados e Discussão}

A análise de variância conjunta, para todos os ensaios, está apresentada na Tabela 1. Para a variável PV, houve resposta significativa para os efeitos de ambientes (local e ano), interação $\mathrm{GxE}(\mathrm{p}<0,01)$ e genótipo $(\mathrm{p}<0,05)$, o que indica que os genótipos apresentam desempenho diferenciado em relação às variações ambientais. No caso do P100G, houve efeito de genótipo, ambiente e interação $\mathrm{GxE}(\mathrm{p}<0,01)$.

Tabela 1. Análise de variância conjunta para produtividade de vagens $\left(\mathrm{kg} \mathrm{ha}^{-1}\right)$, rendimento e peso de 100 grãos de 20 genótipos de amendoim, avaliados em dez ambientes de produção no Estado de São Paulo.

\begin{tabular}{lrcc}
\hline Fonte de variação & GL & \multicolumn{2}{c}{ Quadrado médio } \\
\cline { 3 - 4 } & & $\begin{array}{c}\text { Produtividade } \\
\left(\mathrm{kg} \mathrm{ha}^{-1}\right)\end{array}$ & $\begin{array}{c}\text { Peso de } \\
100 \text { grãos }(\mathrm{g})\end{array}$ \\
\hline Blocos/ambiente & 30 & $1.388 .539,70^{\mathrm{ns}}$ & $46,68^{\text {ns }}$ \\
Genótipos (G) & 19 & $2.241 .381,82^{*}$ & $592,83^{* *}$ \\
Ambientes (E) & 9 & $43.493 .704,76^{* *}$ & $1.359,29^{* *}$ \\
GxE & 171 & $1.405 .879,05^{* *}$ & $30,94^{* *}$ \\
Resíduo & 570 & $687.462,96$ & 15,70 \\
\hline Média & & $5.422,23$ & 69,28 \\
CV $(\%)$ & 15,29 & 5,72 \\
\hline
\end{tabular}

${ }^{n s}$ ão-significativo. $*$ e $* *$ Significativo a 5 e $1 \%$ de probabilidade, respectivamente, pelo teste $\mathrm{F}$. 
No método da ecovalência $\left(\omega_{\mathrm{i}}\right)$, o ordenamento dos genótipos com base na média da PV e do P100G foi utilizado como um indicativo da adaptabilidade. Para a característica PV, as linhagens L144, L125, L137, L148, L147, L132 e L113 apresentaram os menores valores de $\omega_{\mathrm{i}}$, sendo consideradas as mais estáveis (Tabela 2). Destas, a L125, L137, L132 e L113 apresentaram produtividade acima da média geral.

O peso de 100 grãos é uma característica importante na cultura de amendoim, principalmente para atender ao mercado de exportação, que exige cultivares com maior tamanho de grão. Assim, as linhagens L147, L127, L148, L141, L146, L138, L144 e L150 apresentaram P100G acima de $71 \mathrm{~g}$, contudo, foram consideradas instáveis pelo método da ecovalência. As linhagens com menores valores de ecovalência foram L14P, L121 e L149. Entretanto, nenhuma delas apresentou valores acima da média geral de 69,28 g. As cultivares Runner IAC 886 e IAC Caiapó apresentaram valores de 68,91 e 64,02 g, respectivamente (Tabela 3 ).

As estimativas de ecovalência para as características de PV e P100G apresentaram diferenças entre as linhagens/cultivares, o que indica que o genótipo mais estável para PV não o é para P100G.
De acordo com Lin \& Binns (1988), as estimativas de $P_{i}$ podem ser subdivididas em partes atribuídas aos desvios genéticos, que correspondem à soma de quadrados do efeito dos genótipos e desvios devido à interação. Neste caso, para PV, as linhagens L123, L137, L121, L150, L132, L113 e L125 apresentaram os menores valores de $\mathrm{P}_{\mathrm{i}}$ com a maior parte atribuída ao desvio genético (Tabela 2). Todas apresentaram PV acima da média geral e foram consideradas as mais estáveis e produtivas, destacando-se L123, L137 e L150. As cultivares comerciais IAC Caiapó e Runner IAC 886 ficaram na posição 15o e 19o no ranking das mais estáveis, respectivamente. Esse método apontou as três linhagens mais produtivas (L123, L137 e L150) como estáveis. Tal resultado pode ser explicado pelo fato desse método considerar como de maior adaptabilidade e estabilidade os genótipos cujo comportamento em cada ambiente esteja mais próximo do genótipo com melhor comportamento.

Com relação à característica P100G, as linhagens L146, L127, L147, L138, L141 e L148 apresentaram os menores valores de $\mathrm{P}_{\mathrm{i}}$, também com a maior parte atribuída ao desvio genético (Tabela 3). Essas mesmas linhagens apresentaram P100G acima da média geral. De acordo com esse método, as cultivares Runner IAC 886 e

Tabela 2. Estimativas de adaptabilidade e estabilidade para produtividade (PV) (kg ha-1), de acordo com o método de Ecovalência (Wricke, 1964), Lin \& Binns (1988) e Eberhart \& Russel (1966), em genótipos de amendoim avaliados em dez ambientes de produção no Estado de São Paulo(1).

\begin{tabular}{|c|c|c|c|c|c|c|c|c|c|}
\hline \multirow{2}{*}{$\begin{array}{l}\text { Linhagem/ } \\
\text { cultivar }\end{array}$} & \multirow[t]{2}{*}{ Média } & \multirow{2}{*}{$\begin{array}{c}\text { Wricke }(1964) \\
\omega_{\mathrm{i}}\left(\mathrm{x} 10^{5}\right)\end{array}$} & \multicolumn{4}{|c|}{ Lin \& Binns (1988) } & \multicolumn{3}{|c|}{ Eberhart \& Russel (1966) } \\
\hline & & & $\begin{array}{l}P_{i} \text { geral } \\
\left(\mathrm{x} 10^{4}\right) \\
\end{array}$ & $\begin{array}{c}\text { Desvio } \\
\text { genético }\end{array}$ & $\begin{array}{c}\text { Desvio } \\
\text { interação }\end{array}$ & $\begin{array}{c}\text { Contribuição } \\
\text { para interação (\%) }\end{array}$ & $\beta_{\mathrm{i}}$ & $\delta_{\mathrm{ij}}\left(\mathrm{x} 10^{4}\right)$ & $\mathrm{R}^{2}(\%)$ \\
\hline IAC Caiapó & $5384,21(16)$ & $96,98(9)$ & $67,37(15)$ & 54,21 & 13,16 & 3,69 & 0,92 & $11,80(11)$ & 63,46 \\
\hline L113 & $5500,48(7)$ & $80,97(7)$ & $51,91(6)$ & 42,78 & 9,13 & 2,56 & 0,84 & $5,70(8)$ & 64,68 \\
\hline L118 & $5243,77(17)$ & $127,61(15)$ & $86,09(16)$ & 69,82 & 16,27 & 4,57 & 0,74 & $17,73 *(15)$ & 48,55 \\
\hline L121 & $5616,36(4)$ & $100,47(10)$ & $41,72(3)$ & 32,73 & 8,99 & 2,52 & 0,77 & $10,16(10)$ & 56,47 \\
\hline L122 & $5432,32(12)$ & $102,93(11)$ & $67,27(14)$ & 49,32 & 17,95 & 5,04 & 0,88 & $13,14(13)$ & 60,31 \\
\hline L123 & $5720,99(1)$ & $105,08(13)$ & $37,81(1)$ & 24,81 & 13,00 & 3,65 & $0,54 *$ & $1,97(4)$ & 47,34 \\
\hline L125 & $5499,26(8)$ & $49,95(2)$ & $53,56(7)$ & 42,89 & 10,67 & 2,99 & 0,99 & $-2,52(5)$ & 79,51 \\
\hline L127 & $5417,36(13)$ & $294,46(20)$ & 97,91 (17) & 50,81 & 47,10 & 13,22 & $1,65^{* *}$ & $47,97 * *(19)$ & 71,60 \\
\hline L132 & $5493,24(9)$ & $73,90(6)$ & $51,45(5)$ & 43,45 & 8,00 & 2,25 & 0,98 & 4,94 (7) & 71,80 \\
\hline L137 & $5714,86(2)$ & $64,48(3)$ & $41,01(2)$ & 25,25 & 15,77 & 4,43 & 1,16 & $0,37(1)$ & 81,75 \\
\hline L138 & $5457,27(10)$ & $103,84(12)$ & $62,49(9)$ & 46,87 & 15,62 & 4,38 & 0,87 & $13,33(14)$ & 59,70 \\
\hline L141 & $5605,21(5)$ & $162,52(17)$ & $62,37(8)$ & 33,64 & 28,73 & 8,06 & 1,16 & $30,90 * *(17)$ & 63,04 \\
\hline L144 & 4910,76 (19) & $39,32(1)$ & $120,68(18)$ & 114,72 & 5,96 & 1,67 & 1,04 & $-5,97(9)$ & 84,61 \\
\hline L146 & $4881,68(20)$ & $96,78(8)$ & $139,96(20)$ & 119,16 & 20,80 & 5,84 & 1,03 & $1,96(3)$ & 68,32 \\
\hline L147 & $5393,71(15)$ & $71,98(5)$ & $66,67(13)$ & 53,23 & 13,45 & 3,77 & 0,99 & $4,36(6)$ & 72,79 \\
\hline L148 & $5408,54(14)$ & $64,54(4)$ & $64,79(11)$ & 51,71 & 13,09 & 3,67 & 0,86 & $0,85(2)$ & 70,47 \\
\hline L149 & $5452,57(11)$ & $112,30(14)$ & $63,72(10)$ & 47,33 & 16,39 & 4,6 & 1,28 & $11,84(12)$ & 77,23 \\
\hline L14P & $5567,32(6)$ & $219,11(18)$ & $66,11(12)$ & 36,82 & 29,29 & 8,22 & 0,87 & $49,34 * *(20)$ & 40,82 \\
\hline $\mathrm{L} 150$ & $5676,51(3)$ & $151,21(16)$ & $44,54(4)$ & 28,05 & 16,49 & 4,63 & 0,68 & $23,17 *(16)$ & 41,21 \\
\hline Runner IA C886 & $5068,07(18)$ & $285,69(19)$ & $128,57(19)$ & 92,13 & 36,45 & 10,23 & $1,67 * *$ & $43,17 * *(18)$ & 73,70 \\
\hline
\end{tabular}

(1)Números entre parênteses referem-se à classificação dos genótipos em relação a cada parâmetro. * e **Significativo a 5 e $1 \%$ de probabilidade, respectivamente. 
IAC Caiapó ficaram em 8ạ e 20ạ posição, respectivamente, na escala dos genótipos com maior peso de grãos. Das dez linhagens com maior peso de 100 grãos, seis apresentaram os menores valores de $P_{i}$ e foram selecionadas com boa adaptabilidade e estabilidade pelo método de Lin \& Binns (1988).

Pelo método de Eberhart \& Russel (1966), para a característica PV, os genótipos mais estáveis foram L137, L148, L146, L123, L125, L147, L132, L113 e L144, com os menores $\delta_{\mathrm{ij}}$. Contudo, somente as linhagens L137, L125 e L132 apresentaram produtividade acima da média geral e coeficiente de determinação $\left(\mathrm{R}^{2}\right)$ maior do que $70 \%$.

As linhagens L123 e L127 e a cultivar Runner IAC 886 apresentaram desvios de $\beta_{\mathrm{i}}=1$ significativos. A L123 possui adaptabilidade específica aos ambientes desfavoráveis, tendo produzido $5.720,99 \mathrm{~kg} \mathrm{ha}^{-1}$ na média de todos os ambientes, enquanto a L127 e a cultivar Runner IAC 886 apresentaram boa adaptabilidade a ambientes favoráveis, tendo produzido cerca de 5.417,36 e 5.068,07 kg ha-1, respectivamente, sendo responsivas à melhoria do ambiente. Tal observação também pôde ser verificada no método de Lin \& Binns (1988) (Tabela 2).

A linhagem L123 apresentou a maior média de produtividade, combinada com boa estabilidade e adaptabilidade a ambientes menos favoráveis, porém com baixo coeficiente de determinação $\left(R^{2}=47,34 \%\right)$. Mesmo com baixa previsibilidade, essa linhagem possui bom potencial para ser utilizada como genitora em programas de melhoramento. Além disso, as linhagens L150, L141, L14P, L127, L118 e a cultivar Runner IAC 886 apresentaram grandes desvios de regressão, o que indica que as variações de PV, observadas nestes genótipos nos dez ambientes, não foram devidamente representadas pelo modelo de regressão linear.

Com relação à característica P100G, os genótipos que apresentaram os menores valores de $\delta_{\mathrm{ij}}$ foram L148, L122, L123, L144, L125, L138, IAC Caiapó, L137 e L113, tendo sido considerados estáveis para esta característica. Porém, as linhagens L148, L144 e L138 apresentaram pesos de 100 grãos acima da média geral, com $\mathrm{R}^{2}$ de 69,53, 62,44 e 83,48\%, respectivamente. As estimativas de $\beta_{\mathrm{i}}$ não apresentaram diferenças significativas da unidade $\beta_{\mathrm{i}}=1(\mathrm{p}<0,05)$, o que indica boa adaptabilidade geral de todos os genótipos quanto ao peso de 100 grãos. Entretanto, as linhagens L146, L150 e a cultivar Runner IAC 886 apresentaram desvios significativos da regressão. As linhagens L147 e L127 apresentaram as maiores médias de P100G com ampla adaptabilidade, estabilidade média e coeficientes de determinação acima de $77 \%$, porém não foram selecionadas por este método.

Tabela 3. Estimativas de adaptabilidade e estabilidade para peso de 100 grãos (P100G) (g), de acordo com o método de Ecovalência (Wricke, 1964), Lin \& Binns (1988), e Eberhart \& Russel (1966), em genótipos de amendoim avaliados em dez ambientes de produção no Estado de São Paulo(1).

\begin{tabular}{|c|c|c|c|c|c|c|c|c|c|}
\hline \multirow{2}{*}{$\begin{array}{l}\text { Linhagem/ } \\
\text { cultivar }\end{array}$} & \multirow[t]{2}{*}{ Média } & \multirow{2}{*}{$\begin{array}{c}\text { Wricke (1964) } \\
\omega_{\mathrm{i}}\end{array}$} & \multicolumn{4}{|c|}{ Lin \& Binns (1988) } & \multicolumn{3}{|c|}{ Eberhart \& Russel (1966) } \\
\hline & & & $\mathrm{P}_{\mathrm{i}}$ geral & $\begin{array}{c}\text { Desvio } \\
\text { genético }\end{array}$ & $\begin{array}{c}\text { Desvio } \\
\text { interação }\end{array}$ & $\begin{array}{c}\text { Contribuição } \\
\text { para interação (\%) }\end{array}$ & $\beta_{\mathrm{i}}$ & $\delta_{\mathrm{ij}}$ & $\mathrm{R}^{2}(\%)$ \\
\hline IAC Caiapó & $64,02(20)$ & $181,34(10)$ & $202,40(20)$ & 152,38 & 50,02 & 4,81 & 1,02 & $-3,92(7)$ & 77,62 \\
\hline L113 & $66,49(15)$ & $134,79(5)$ & $164,93(15)$ & 112,28 & 52,64 & 5,06 & 0,99 & $-4,97(9)$ & 79,98 \\
\hline L118 & $65,15(18)$ & $135,30(6)$ & $188,21(18)$ & 133,34 & 54,87 & 5,27 & 0,91 & $-5,13(12)$ & 77,82 \\
\hline L121 & $64,78(19)$ & $86,64(2)$ & $192,87(19)$ & 139,47 & 53,4 & 5,13 & 1,01 & $-6,54(15)$ & 86,18 \\
\hline L122 & $67,09(13)$ & $291,82(14)$ & $149,52(11)$ & 103,47 & 46,05 & 4,43 & 1,00 & $-1,06(2)$ & 69,12 \\
\hline L123 & $66,15(16)$ & $337,05(16)$ & $180,21(16)$ & 117,52 & 62,68 & 6,02 & 0,95 & $2,14(3)$ & 59,44 \\
\hline L125 & $68,39(10)$ & $212,67(12)$ & $141,61(10)$ & 85,71 & 55,9 & 5,37 & 1,18 & $-2,79(5)$ & 79,56 \\
\hline L127 & $75,47(2)$ & $161,96(8)$ & $61,26(2)$ & 18,06 & 43,2 & 4,15 & 0,85 & $-5,67(13)$ & 77,69 \\
\hline L132 & $65,28(17)$ & $153,66(7)$ & $187,54(17)$ & 131,19 & 56,35 & 5,41 & 0,78 & $-5,03(10)$ & 71,4 \\
\hline L137 & $67,56(11)$ & $115,16(4)$ & $158,02(14)$ & 96,82 & 61,2 & 5,88 & 1,03 & $-4,55(8)$ & 79,74 \\
\hline L138 & $73,53(6)$ & $298,02(15)$ & $75,70(4)$ & 31,62 & 44,09 & 4,24 & 1,32 & $-3,10(6)$ & 83,48 \\
\hline L141 & $73,98(4)$ & $493,20(17)$ & $80,27(5)$ & 28,14 & 52,13 & 5,01 & 1,03 & $5,98(14)$ & 56,35 \\
\hline L144 & $73,09(7)$ & $193,51(11)$ & $101,10(7)$ & 35,18 & 65,92 & 6,33 & 0,78 & $-2,67(4)$ & 62,44 \\
\hline L146 & $73,74(5)$ & $525,34(18)$ & $37,27(1)$ & 29,91 & 7,36 & 0,71 & 1,25 & $17,25^{* *}(20)$ & 13,87 \\
\hline L147 & $75,57(1)$ & $166,27(9)$ & 70,93 (3) & 17,43 & 53,49 & 5,14 & 1,25 & $-5,10(11)$ & 86,70 \\
\hline L148 & $74,25(3)$ & $269,16(13)$ & $83,91(6)$ & 26,14 & 57,77 & 5,55 & 1,05 & $-0,39(1)$ & 69,53 \\
\hline L149 & $66,73(14)$ & $94,20(3)$ & $151,52(12)$ & 108,77 & 42,75 & 4,11 & 0,84 & $-7,83(17)$ & 88,22 \\
\hline L14P & $67,21(12)$ & $79,53(1)$ & $155,25(13)$ & 101,74 & 53,51 & 5,14 & 0,94 & $-6,81(16)$ & 85,67 \\
\hline $\mathrm{L} 150$ & $71,50(8)$ & $554,96(19)$ & $128,30(9)$ & 49,77 & 78,53 & 7,55 & 1,16 & $9,76 *(18)$ & 57,06 \\
\hline Runner IAC 886 & $68,91(9)$ & $805,46(20)$ & $127,79(8)$ & 78,98 & 48,81 & 4,69 & 0,66 & $12,58 *(19)$ & 27,09 \\
\hline
\end{tabular}

(1)Números entre parênteses referem-se à classificação dos genótipos em relação a cada parâmetro. * e **Significativo a 5 e $1 \%$ de probabilidade, respectivamente. 
Considerando-se os três métodos estudados, verificase que as linhagens que apresentaram boa estabilidade produtiva e PV acima da média geral foram L125, L132, L113 e L137, com produtividade média de 5.499,26, $5.493,24,5.500,48$ e 5.714,86 $\mathrm{kg} \mathrm{ha}^{-1}$, respectivamente (Tabela 2). Para PV, o método de Lin \& Binns (1988) foi capaz de discriminar todas as linhagens selecionadas pelos métodos da ecovalência e de Eberhart \& Russel (1966), tendo apontado, ainda, as linhagens L121 e L123 como estáveis e produtivas.

Para a característica P100G, não houve linhagens comuns aos três métodos, uma vez que as três linhagens (L14P, L121 e L149) selecionadas pelo método da ecovalência não possuem peso de 100 grãos acima da média geral. Os métodos de Lin \& Binns (1988) e Eberhart \& Russel (1966) apontaram as mesmas linhagens estáveis e produtivas, com exceção da linhagem L144, e demonstraram, ainda, que as linhagens L127, L141, L146 e L147 apresentam grande potencial quanto à estabilidade e produtividade. Neste caso, as linhagens L138 e L148 foram comuns, conforme Lin \& Binns (1988) e Eberhart \& Russel (1966).

A cultivar IAC Caiapó, tida como estável em diferentes ambientes de produção (Godoy et al., 1999), apresentou comportamento intermediário quanto à $\mathrm{PV}$, pelos métodos de ecovalência e de Lin \& Binns (1988). De acordo com as análises pelo método de Eberhart \& Russel (1966), essa cultivar revelou o mesmo comportamento em relação à estabilidade $\left(\delta_{\mathrm{ij}}\right)$, possui ampla adaptabilidade $\left(\beta_{\mathrm{i}}=0,92\right)$ e produtividade de $5.384,21 \mathrm{~kg} \mathrm{ha}^{-1}$. A cultivar Runner IAC 886 mostrou potencial de PV abaixo da média geral $\left(5.068,07 \mathrm{~kg} \mathrm{ha}^{-1}\right)$, tendo revelado baixa estabilidade de produção segundo os métodos de ecovalência e de Lin \& Binns (1988). Além disso, de acordo com o método de Eberhart \& Russel, possui boa adaptabilidade a ambientes favoráveis e grandes desvios da regressão linear.

Em relação à comparação dos métodos, Prado et al. (2001) utilizaram os métodos de ecovalência, Cruz et al. (1989) e Eberhart \& Russel (1966), na avaliação de cultivares de soja, e concluíram que os métodos utilizados foram coerentes entre si, permitindo a identificação das cultivares com maior estabilidade e adaptabilidade. Observaram também que o comportamento produtivo das cultivares de soja ao longo das épocas de plantio foi mais bem representado pelo modelo linear proposto por Eberhart \& Russell (1966).
Por meio da análise dos dados deste trabalho, os métodos de Lin \& Binns (1988) e Eberhart \& Russel (1966) foram coerentes entre si e permitem identificar entre as linhagens/cultivares avaliadas, as de maior estabilidade e adaptabilidade. É possível inferir que o método de Lin \& Binns (1988) permitiu a seleção de maior número de linhagens mais estáveis e produtivas e foi, portanto, mais discriminante com relação à estabilidade dos genótipos. Contudo, o método de Eberhart \& Russel (1966) fornece maiores informações sobre o ajuste dos dados, ao modelo de regressão, e indicações de genótipos com adaptabilidade ampla ou específica a ambientes favoráveis e desfavoráveis.

A correlação entre as estimativas de adaptabilidade ou estabilidade com o uso de diferentes métodos pode contribuir para melhor predição do comportamento dos genótipos avaliados. Em relação ao coeficiente de correlação de Spearman, foi observada correlação negativa $(p<0,01)$ entre a produtividade de vagens e o parâmetro $\mathrm{P}_{\mathrm{i}}$, e correlação positiva $(\mathrm{p}<0,01)$ entre $\delta_{\mathrm{ij}}$ e $\omega_{\mathrm{i}}$ (Tabela 4). Isto significa que quanto maior o valor da média de produtividade de vagens do genótipo, menor é o valor de $\mathrm{P}_{\mathrm{i}}$ corroborando as teorias de Lin \& Binns (1988). A tendência positiva era esperada, uma vez que o parâmetro $\beta_{\mathrm{i}}$ aumenta à medida que a linhagem possui maiores valores médios de PV, para grande parte dos ambientes. A correlação entre $\delta_{\mathrm{ij}} \mathrm{e} \omega_{\mathrm{i}}$ foi bastante alta (92\%), o que indica que quanto maior o desvio do modelo de regressão, maior é o parâmetro de ecovalência.

Analisando-se a característica P100G, foram detectadas as mesmas correlações de PV, além da correlação negativa entre $P_{i}$ e $\omega_{i}(p<0,05)$ (Tabela 5). A princípio, essa observação é contraditória, tendo-se em vista que os métodos de ecovalência e de Lin \& Binns (1988) estabelecem que genótipos com menores valores de $\mathrm{P}_{\mathrm{i}}$ e $\omega_{\mathrm{i}}$ são os mais estáveis. Assim, as correlações porventura existentes deveriam ser positivas. Contudo, o método de ecovalência estima a

Tabela 4. Coeficientes de correlação de Sperman entre a média de produtividade de vagens (PV) de 20 genótipos de amendoim e os parâmetros $\omega_{\mathrm{i}}$ de ecovalência, $\mathrm{P}_{\mathrm{i}}$ de Lin \& Binns (1988) e $\beta_{\mathrm{i}}$ e $\delta_{\mathrm{ij}}$ de Eberhart \& Russel (1966).

\begin{tabular}{lcccc}
\hline & $\beta_{\mathrm{i}}$ & $\delta_{\mathrm{ij}}$ & $\mathrm{P}_{\mathrm{i}}$ & $\omega_{\mathrm{i}}$ \\
\hline $\mathrm{PV}$ & $-0,37^{\mathrm{ns}}$ & $-0,06^{\mathrm{ns}}$ & $-0,92^{* *}$ & $0,10^{\mathrm{ns}}$ \\
$\beta_{\mathrm{i}}$ & - & $0,09^{\mathrm{ns}}$ & $0,34^{\mathrm{ns}}$ & $0,03^{\mathrm{ns}}$ \\
$\delta_{\mathrm{ij}}$ & - & - & $0,34^{\mathrm{ns}}$ & $0,92^{* *}$ \\
$\mathrm{P}_{\mathrm{i}}$ & - & - & - & $0,17^{\mathrm{ns}}$ \\
\hline ns Não-significativo. & $*$ e $* *$ Significativo a 5 e $1 \%$ de probabilidade, \\
respectivamente.
\end{tabular}


Tabela 5. Coeficientes de correlação de Sperman entre a média de peso de 100 grãos (P100G) de 20 genótipos de amendoim e os parâmetros $\omega_{\mathrm{i}}$ de ecovalência, $\mathrm{P}_{\mathrm{i}}$ de Lin \& Binns (1988) e $\beta_{\mathrm{i}}$ e $\delta_{\mathrm{ij}}$ de Eberhart \& Russel (1966).

\begin{tabular}{lcccc}
\hline & $\beta_{\mathrm{i}}$ & $\delta_{\mathrm{ij}}$ & $\mathrm{P}_{\mathrm{i}}$ & $\omega_{\mathrm{i}}$ \\
\hline $\mathrm{P} 100 \mathrm{G}$ & $0,39^{\mathrm{ns}}$ & $0,34^{\mathrm{ns}}$ & $-0,96^{* *}$ & $0,43^{\mathrm{ns}}$ \\
$\beta_{\mathrm{i}}$ & - & $0,29^{\mathrm{ns}}$ & $-0,37^{\mathrm{ns}}$ & $0,30^{\mathrm{ns}}$ \\
$\delta_{\mathrm{ij}}$ & - & - & $-0,38^{\mathrm{ns}}$ & $0,93^{* *}$ \\
$\mathrm{P}_{\mathrm{i}}$ & - & - & - & $-0,51^{*}$ \\
\hline
\end{tabular}

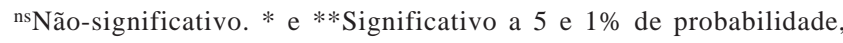
respectivamente.

contribuição de cada genótipo para a interação GxE total, por meio da soma de quadrados da interação, envolvendo todos os ambientes onde esse genótipo foi avaliado, o que não está diretamente envolvido com o princípio proposto por Lin \& Binns (1988). Daí a contradição na escolha das linhagens de amendoim mais estáveis para P100G, uma vez que nenhuma linhagem selecionada pelo método de ecovalência o foi nos outros métodos.

Correlações positivas entre produtividade de grãos de soja (PG) e o parâmetro $\beta_{\mathrm{i}}$, $\delta_{\mathrm{ij}}$ e $\mathrm{S}_{\mathrm{i}}{ }^{3}$, $\delta_{\mathrm{ij}}$ e soma de "rank" (Hühn, 1996), e correlações negativas entre $\beta_{\mathrm{i}} \mathrm{e}$ $\mathrm{P}_{\mathrm{i}}$, PG e $\mathrm{P}_{\mathrm{i}}$, PG e a soma de "rank" foram observadas por Dashiell et al. (1994). Scapim et al. (2000) encontraram correlação negativa $(p<0,01)$ entre o $\beta_{i}$ e o $P_{i}$, que mostra que as cultivares mais responsivas tendem a possuir menores valores de $\mathrm{P}_{\mathrm{i}}$, e correlação positiva ( $<<0,05)$ com o parâmetro $\mathrm{S}_{\mathrm{i}}{ }^{(1)}$ de Huehn (1990), o que indica que genótipos superiores podem ser estáveis. Além disso, não houve correlação entre $P_{i}$ e os parâmetros $\mathrm{S}_{\mathrm{i}}^{(2)}$ e $\mathrm{S}_{\mathrm{i}}^{\left({ }^{(3)}\right.}$ de Huehn (1990) e $\delta_{\mathrm{ij}}$ de Eberhart \& Russel (1966).

\section{Conclusões}

1. As linhagens L123, L137, L113 e L150 são as mais estáveis, considerando-se os três métodos utilizados.

2. O método de Lin \& Binns é mais discriminante do que os outros métodos, na avaliação da estabilidade e da produtividade das linhagens/cultivares utilizadas.

3. O método de Eberhart \& Russel fornece maiores informações na indicação das linhagens com adaptabilidade ampla ou específica a ambientes favoráveis e desfavoráveis.

4. Os métodos de Lin \& Binns e Eberhart \& Russel são mais informativos que o de ecovalência, na identificação de linhagens/cultivares de amendoim mais produtivas e estáveis, para as características produtividade de vagens e peso de 100 grãos.

\section{Referências}

ALLARD, R.W. Princípios do melhoramento genético. São Paulo: Edgard Blüchner, 1971. 381p.

CARBONELL, S.A.M.; AZEVEDO FILHO, J.A.; DIAS, L.A.S.; GONÇALVES, C.; ANTÔNIO, C.B. Adaptabilidade e estabilidade de produção de cultivares e linhagens de feijoeiro no Estado de São Paulo. Bragantia, v.60, p.69-77, 2001.

CROSSA, J. Statistical analysis of multilocal trials. Advances in Agronomy, v.44, p.55-85, 1990.

CRUZ, C.D. Programa GENES: aplicativo computacional em genética e estatística (software). Viçosa: Imprensa Universitária, 2001. 642p.

CRUZ, C.D.; REGAZZI, A.J. Modelos biométricos aplicados ao melhoramento genético. 2.ed. Viçosa: UFV, 2001. 390p.

CRUZ, C.D.; TORRES, R.A.; VENCOVSKY, R. An alternative approach to the stability analysis proposed by Silva e Barreto. Revista Brasileira de Genética, v.12, p.567-580, 1989.

DASHIEL, K.E.; ARIYO, O.J.; BELLO, L.; OJO, K. Genotype x environment interaction and simultaneous selection for high yield and stability in soybeans (Glycine max (L.) Merril). Annals of Applied Biology, v.124, p.133-139, 1994.

EBERHART, S.A.; RUSSEL, W.A. Stability parameters for comparing varieties. Crop Science, v.6, p.36-40, 1966.

GAUCH, H.G.; ZOBEL, R.W. AMMI analysis of yield trials. In: KANG, M.S.; GAUCH, H.G. (Ed.). Genotype by environment interaction. Boca Raton: CRC Press, 1996. p.85-122.

GODOY, I.J. Produção de amendoim com qualidade. Viçosa: CPT, 2005. 139p.

GODOY, I.J.; MORAES, S.A.; MORAES, A.R.A.; KASAI, F.S.; MARTINS, A.L.M.; PEREIRA, J.C.V.N.A. Potencial produtivo de linhagens de amendoim do grupo ereto precoce com e sem controle de doenças foliares. Bragantia, v.60, p.101-110, 2001.

GODOY, I.J.; MORAES, S.A.; SIQUEIRA, W.J.; PEREIRA, J.C.V.N.A.; MARTINS, A.L.M.; PAULO, E.M. Produtividade, estabilidade e adaptabilidade de cultivares de amendoim em três níveis de controle de doenças foliares. Pesquisa Agropecuária Brasileira, v.34, p.1183-1191, 1999.

HOPKINS, A.A.; VOGEL, K.P.; MOORE, K.J.; JOHNSON, K.D.; CARLSON, I.T. Genotype effects and genotype by environment interactions for traits of elite switchgrass populations. Crop Science, v.35, p.125-132, 1995.

HUEHN, M. Nonparametric measures of phenotypic stability. Part 1: theory. Euphytica, v.47, p.189-194, 1990.

HÜHN, M. Nonparametric analysis of genotype $\mathrm{x}$ environment interactions by ranks. In: KANG, M.S.; GAUCH, H.G. (Ed.). Genotype-by-environment interactions. Boca Raton: CRC Press, 1996. p.235-270. 
LIN, C.S.; BINNS, M.R. A superiority measure of cultivar performance for cultivar x location data. Canadian Journal of Plant Science, v.68, p.193-198, 1988.

MAGARI, R.; KANG M.S. SAS STABLE: stability analysis of balanced and unbalanced data. Agronomy Journal, v.89, p.929-932, 1997.

PRADO, E.E.; HIROMOTO, D.M.; GODINHO, V.P.C.; UTUMI, M.M.; RAMALHO, A.R. Adaptabilidade e estabilidade de cultivares de soja em cinco épocas de plantio no cerrado de Rondônia. Pesquisa Agropecuária Brasileira, v.36, p.625-635, 2001.

ROSSE, L.N.; VENCOVSKY, R. Modelo de regressão não linear aplicado ao estudo da estabilidade fenotípica de genótipos de feijão do Estado do Paraná. Bragantia, v.59, p.97-107, 2000.

SAS INSTITUTE (Cary, Estados Unidos). Software and services: system for Windows, versão 8.0: software. Cary, 2000. 1v.
SCAPIM, C.A.; OLIVEIRA, V.R.; BRACCINI, A.D.E.; CRUZ, C.D.; ANDRADE, C.A.B.; VIDIGAL, M.C.G. Yield stability in maize (Zea mays L.) and correlations among the parameters of the Eberhart and Russell, Lin and Binns and Huehn models. Genetics and Molecular Biology, v.23, p.387-393, 2000.

SILVA, W.C.J.; DUARTE, J.B. Statistical methods to study phenotypic adaptability and stability in soybean. Pesquisa Agropecuária Brasileira, v.41, p.23-30, 2006.

TOLER, J.E.; BURROWS, P.M. Genotypic performance over environmental arrays: a non linear grouping protocol. Journal of Applied Statistics, v.25, p.131-143, 1998.

WRICKE, G. Zur Berechning der Ökovalenz bei Sommerweizen und Hafer. Zeitschrift fur Pflanzenzüchtung, v.52, p.127-138, 1964.

Recebido em 27 de janeiro de 2006 e aprovado em 19 de abril de 2006 